\title{
Association of BDNF Serum Concentrations with Central Serotonergic Activity: Evidence from Auditory Signal Processing
}

\author{
Undine E Lang', Rainer Hellweg² and Jürgen Gallinat*,3 \\ 'Department of Neurology, University of Tuebingen, Tuebingen, Germany; ${ }^{2}$ Clinic for Psychiatry and Psychotherapy, Charité Medicine Berlin, \\ Campus Benjamin Franklin, Germany; ${ }^{3}$ Clinic for Psychiatry and Psychotherapy, Charité Medicine Berlin, Campus Charité Mitte, Germany
}

\begin{abstract}
Disturbances of serotonergic neurotransmission in the brain have been implicated in the pathogenesis and maintenance of several psychiatric disorders. According to recent preclinical and clinical studies, the loudness dependence of auditory evoked potentials (LD) is related to the central serotonergic neurotransmission in humans. As the serotonergic phenotype has been reported to be associated with brain-derived neurotrophic factor (BDNF), we studied whether BDNF serum concentrations are related to LD in I09 healthy human volunteers (62 male, 47 female, age: $42.5 \pm 13.1$ years). Pearson correlation showed a significant negative correlation between the BDNF serum concentrations and the LD measured at Fz $(r=-0.259, p=0.007)$ and a trend for the $\mathrm{Cz}$ electrode $(r=-0.185$, $p=0.055)$. Although this association needs to be replicated, the results are in line with the assumption that low serum BDNF levels reflect low central serotonergic neurotransmission as indicated by a strong LD.

Neuropsychopharmacology (2005) 30, I |48-I I53, advance online publication, 19 January 2005; doi: I 0. I 038/sj.npp. I 300666
\end{abstract}

Keywords: BDNF; brain-derived neurotrophic factor; evoked potentials; loudness dependence; healthy volunteers; neuroticism; serotonin

\section{INTRODUCTION}

Disturbances of serotonin neurotransmission in the brain have been implicated in the pathogenesis and maintenance of several psychiatric disorders and symptoms, that is, depression, alcoholism, impulse control disorders, aggression, suicidal behavior, anxiety, and obsessive compulsive behavior (Senkowski et al, 2003; Heinz et al, 2001; Petty et al, 1996). The monoamine hypothesis of depression was first formulated 40 years ago (Schildkraut, 1965). For instance, levels of the major serotonin metabolite 5-hydroxyindoleacetic acid (5-HIAA) have been reported to be lower than normal in the cerebrospinal fluid of patients with depression (Cheetham et al, 1991), although this is not a consistent finding (Gjerris, 1988). A relatively reliable observation is that activity of the serotonin transporter in platelets is reduced in patients with depression, a model for neuronal serotonin activity (Owens and Nemeroff, 1994). In line with this, an investigation with $\beta$-CIT single photon emission computed tomography

*Correspondence: Dr J Gallinat, Psychiatrische Universitätsklinik der Charité, im St. Hedwig-Krankenhaus, Örtlicher Bereich Moabit, Turmstr. 21, 10559 Berlin, Germany, Tel: + 4930 231। 2895, Fax: + 4930 23II 2903, E-mail: juergen.gallinat@charite.de

Received 9 September 2004; revised 8 November 2004; accepted I December 2004

Online publication: 12 July 2004 at http://www.acnp.org/citations/ NPPI 207040404 I0/default.pdf reported evidence for a reduction in the activity of the transpoter in patients with depression compared with healthy controls (Malison et al, 1998). Moreover, an increase in the density of postsynaptic cortical 5-HT2 receptor-binding sites of depressed suicide victims and unmedicated depressed patients have been observed by post-mortem studies (Stanley and Mann, 1983; Yates et al, 1990) and PET investigations (Biver et al, 1997). It has been suggested that upregulation of cortical 5-HT2 receptors in depression is an adaptive response to reduced synaptic serotonin (Owens and Nemeroff, 1994).

In recent years, growth and function of monoaminecontaining neurons have been extensively investigated with respect to neurotrophins. It has been suggested that depression or pathophysiological subgroups of depressive disorders may constitute a subtle form of neurotrophinrelated neurodegeneration affecting serotonergic neurons (Altar, 1999; Duman et al, 1997). The neurotrophin brainderived neurotrophic factor (BDNF) influences the phenotype, structural plasticity, and survival of serotonergic neurons (Eaton et al, 1995; Mamounas et al, 1995; Siuciak et al, 1996). In particular, BDNF promotes the sprouting of mature, uninjured serotonergic axons and chronic treatment with BDNF leads to enhancement of the regenerative sprouting of serotonergic axons, damaged by the neurotoxin p-chloroamphetamine (Mamounas et al, 1995, 2000). This BDNF-related stimulation of serotonergic phenotype, in terms of increased neuronal number and neuritic extension, 
would suggest that an increased serotonergic transmission is possibly underlying the antidepressant-like effects reported for BDNF (Siuciak et al, 1997).

The BDNF-mediated stimulation of the neuronal serotonergic phenotype is likely mediated by tyrosine kinase receptor (TrkB)-dependent mechanisms (Rumajogee et al, 2002). Moreover, an upregulation of tryptophan hydroxylase mRNA - the rate-limiting enzyme in serotonin synthesis - has been demonstrated after BDNF injection in rat raphe nuclei (Siuciak et al, 1998).

With respect to human electrophysiology, efforts have been directed to identify indicators of central neurotransmitter activity. Since evidence for a modulation of the loudness dependence (LD) of the auditory evoked N1/P2component by changes of the central serotonergic activity was reported in humans (von Knorring and Perris, 1981) and animals (Juckel et al, 1997, 1999) the LD was hypothesized to be such an indicator (Hegerl and Juckel, 1993). The LD denotes the amplitude change of auditory evoked potentials (AEPs) in response to different stimulus intensities. A strong LD has been proposed to indicate a low serotonergic activity and vice versa. For example, the LD in behaving cats was found being decreased by application of the 5-HT1a-receptor agonist 8-OH-DPAT and increased by the 5-HT2-receptor antagonist ketanserin (Juckel et al, 1997). Empirical clinical support for this hypothesis comes from studies showing that a strong LD in depressed patients is related to a favorable therapeutical outcome to serotonin agonistic agents (Gallinat et al, 2000; Hegerl and Juckel, 1993). Moreover, intraindividual changes of blood serotonin concentrations were negatively correlated with corresponding changes of the LD in patients with major depression (Hegerl et al, 1991). Furthermore, a strong LD was described in abstinent ecstasy users which are hypothesized to possess a diminished serotonergic activity (Tuchtenhagen et al, 2000), while patients with a serotonin syndrome, a possible side effect during SSRI treatment characterized by confusion, restlessness, myoclonus, and hyperthermia, were shown to have a weak LD (Hegerl et al, 1998). Also a significant effect of a functional polymorphism in the promoter region of the serotonin transporter gene 5HTTLPR on the AEP intensity dependence has been observed (Gallinat et al, 2003).

In the present study, the LD was employed as indicator of the central serotonergic activity in humans to test the following hypothesis: A low concentration of serum BDNF is associated with a high LD indicating a low central serotonergic activity. This hypothesis was investigated in 109 carefully selected healthy subjects, who were also have been part of previously investigated samples (Lang et al, 2004; Gallinat et al, 2003).

\section{SUBJECTS AND METHODS}

\section{Subjects}

The study was approved by the ethics committee of the University Hospital Benjamin-Franklin, Free University of Berlin (Germany). All subjects were recruited by newspaper advertisement and gave written informed consent. The participants, who were of German descent, were interviewed by a research psychiatrist with structured clinical interviews
(Mini-International Neuropsychiatric Interview, Sheehan et al, 1998). Exclusion criteria were axis-I or axis-II disorders, alcohol or illegal drug abuse, hearing disorder, significant cardiovascular, hepatic, renal, gastrointestinal, metabolic, or other systemic disease, concurrent psychiatric or neurological illness, organic mental disorder, seizure disorder, mental retardation, Parkinson's disease, toxic central nervous system depression, or any clinically relevant abnormalities. For further description, see Gallinat et al (2002).

Our study subjects were selected from a larger sample $(n=376)$ on the basis of the availability of electrophysiological data, BDNF serum concentrations, and NEO-FFI personality inventory (Costa and McCrae, 1992). A total of 109 healthy unrelated volunteers (62 male, 47 female, age: $42.52 \pm 13.1)$ were investigated. All participants were also part of a sample $(n=118)$ reporting a correlation between BDNF serum concentration and personality traits (Lang et al, 2004) as well as part of a sample $(n=185)$ analysing the association between allelic variants of the serotonin transporter gene and the LD (Gallinat et al, 2003).

\section{Measurement of LD}

Recording took place in an electrically shielded and soundattenuated room adjacent to the recording apparatus (Synamps, Neuroscan ${ }^{\circledR}$ ). Subjects were seated with open eyes in a slightly reclined chair with a head rest and were asked to look at the wall $3 \mathrm{~m}$ in front of them. Evoked responses were recorded with 32 electrodes referred to $\mathrm{Cz}$. Pure sinus tones $(1000 \mathrm{~Hz}, 40 \mathrm{~ms}$ duration with $10 \mathrm{~ms}$ riseand $10 \mathrm{~ms}$ fall time, ISI randomized between 1800 and $2200 \mathrm{~ms})$ of five intensities $(79,87.5,96,104.5,113 \mathrm{~dB}$ sound pressure level) were presented binaurally in a pseudorandomized form by audiometry-headphones. Data were collected with a sampling rate of $250 \mathrm{~Hz}$ and an analogous bandpass filter $(0.16-50 \mathrm{~Hz})$. In all, $350 \mathrm{~ms}$ prestimulus and $800 \mathrm{~ms}$ poststimulus periods were evaluated for 100 sweeps of every intensity (all together 500 sweeps). Before averaging, the first five sweeps were excluded in order to reduce short-term habituation effects. For artefact suppression, all trials were automatically excluded from averaging, if the voltage exceeded $\pm 100 \mu \mathrm{V}$ in any one of the 32 channels at any time point of the averaging period. For each subject, the remaining sweeps were averaged separately for the five stimulus intensities. At least 30 artefact-free sweeps/intensity had to be averaged. N1-peaks $(50-150 \mathrm{~ms})$ and P2-peaks (100-250 ms) were determined semiautomatically at the Fz- and $\mathrm{Cz}$ electrode (referred to linkedmastoids). The LD was calculated as linear regression slope with stimulus intensity as independent and N1/P2-amplitude as dependent variable (Gallinat et al, 2000).

\section{Measurement of BDNF Levels}

Endogenous levels of BDNF were measured in the rethawed serum samples using commercial ELISA kits in principle according to the manufacturer's instructions (Promega Inc., Mannheim, Germany), but adapted to the fluorometric technique used also for nerve growth factor determination (Hellweg et al, 2003) and described in detail previously 
(Hellweg et al, 1989). The BDNF content was expressed as equivalents of recombinant human BDNF. The detection limit of the assay was $1 \mathrm{pg} / \mathrm{ml}$. Determinations of recovery, specific and unspecific neurotrophin binding (the latter against mouse IgG 1 obtained from MOPC 21) involved quadruplicate fluorescence determinations for each serum sample (Hellweg et al, 2003).

\section{Data Analysis}

Kolmogorov-Smirnov test were employed to evaluate whether BDNF level is a normally distributed trait. Gender effects were tested using $T$-test for independent samples, age effects were determined with Pearson's correlation test. BDNF was correlated with the LD using partial correlation test (controlled for age). Results are presented as means \pm one standard deviation. Analyses were computed using statistical software (SPSS $11.5^{\circledR}$ ). A $p$-value of $p<0.05$ was considered significant, while $p<0.10$ was accepted in order to detect trends.

\section{RESULTS}

BDNF serum levels in the healthy human population amounted to $16.69 \pm 7.7 \mathrm{ng} / \mathrm{ml}$, the median amounted to $14.77 \mathrm{pg} / \mathrm{ml}$. Kolmogorov-Smirnov test $(D=1.155, p=$ 0.139) showed that the BDNF serum concentrations in our sample were normally distributed. BDNF concentrations correlated significantly with age $(r=0.200, p=0.037)$, but showed no gender differences (male $16.40 \pm 7.6$, female $17.07 \pm 7.8 \mathrm{ng} / \mathrm{ml} ; T=0.451, \mathrm{df}=107, p=0.653 ; T$-Test $)$.

Age was negatively correlated with the LD measured at the Fz electrode $(r=-0.226 ; p=0.018)$ as well as $\mathrm{Cz}$ electrode $(r=-0.294 ; p=0.002)$. No gender effects were observed for the LD on both electrodes $\mathrm{Fz}(T=0.857$; $\mathrm{df}=107 ; p=0.393)$ and $\mathrm{Cz}(T=1.047 ; \mathrm{df}=107 ; p=0.298)$.

Pearson correlation showed a significant negative correlation between the BDNF concentrations and the LD measured at Fz $(r=-0.259, p=0.007$; see Figure 1$)$ and a trend for the $\mathrm{Cz}$ electrode $(r=-0.185, p=0.055)$. The association between BDNF concentrations and the LD at $\mathrm{Fz}$ was also significant when a partial correlation (controlled for age) was performed $(r=-0.223, p=0.020)$, while the correlation at the $\mathrm{Cz}$ electrode controlled for age was not significant $(r=-0.135, p=0.165)$.

As previously reported (Lang et al, 2004; $n=118$ ), a significant negative correlation between BDNF serum concentration and the depression-related personality trait neuroticism was observed. This was also observed in the present subsample $(n=109 ; r=-0.193 ; p=0.048$; partial correlation controlled for age), indicating a lower BDNF concentration in subjects with a more depressed personality trait. To further investigate the link between behavior and serotonin, it was analyzed if more depressed individuals have lower serotonergic activity, which would be indicated by a higher LD. However, the correlation between neuroticism score and LD did not show a significant result (Fz: $r=0.121, p=0.218$; Cz: $r=0.100, p=0.306$; partial correlation controlled for age).

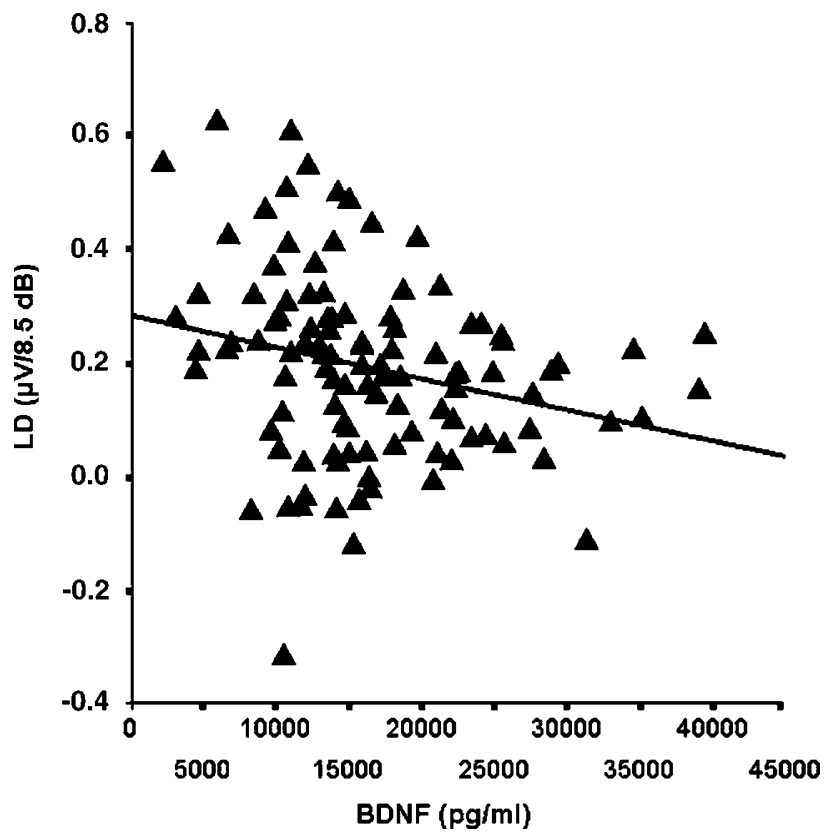

Figure I Correlation between BDNF serum concentration and the LD (Fz electrode referred to linked mastoids) in 109 healthy subjects ( $r=-0.259, p=0.007$; Pearson).

\section{DISCUSSION}

In the present study, a negative correlation between BDNF serum concentrations and $\mathrm{LD}$ measured at $\mathrm{Fz}(p=0.007)$ and a trend in the same direction measured at $\mathrm{Cz}$ $(p=0.055)$ was observed in healthy subjects. This result is compatible with the hypothesis that low concentrations of BDNF are associated with low levels of central serotonergic activity.

In line with this result, an augmentation of serotonergic activity within various brain areas following infusion of BDNF into the midbrain has been reported (Altar et al, 1994; Siuciak et al, 1996). Others observed a dosedependent reduction of the serotonin uptake in B lymphoblasts after exposure to BDNF (Mössner et al, 2000). Apart from immediate serotonergic effects, BDNF has been reported to play a role in the development of serotonergic neurons (Eaton et al, 1995) as well as sprouting of serotonergic axons (Mamounas et al, 1995), which also may affect serotonergic function as indicated by the LD.

Recent basic and clinical research studies have shown evidence for a 'neurotrophin hypothesis' of depression (Garza et al, 2004; Manji et al, 2003; Russo-Neustadt, 2003; D'Sa and Duman, 2002; Duman et al, 1997). This hypothesis may be integrated with the long hypothesized role of monoamines in depression, since evidence for an association of BDNF and serotonin has been presented. For instance, animal studies reported that hippocampal BDNF mRNA levels are significantly increased after physical exercise, administered antidepressant medications and electroconvulsive therapy (Russo-Neustadt, 2003; RussoNeustadt et al, 2000; Nibuya et al, 1995), while in turn, physical exercise, antidepressants (Meeusen et al, 1996; Chaouloff, 1994; Dey et al, 1992; Chaouloff et al, 1986), and electroconvulsive therapy (Gur et al, 2002; Shen et al, 2001) 
have been shown to increase serotonergic neurotransmission. Interestingly, behavioral antidepressant-like properties of BDNF in animal models have been reported (Shirayama et al, 2002; Siuciak et al, 1997). This scenario is compatible with recent investigations supporting the serotonin deficit hypothesis in depression: A study employing $\alpha$-methyl-tryptophan positron emission tomography found evidence for a reduced serotonin synthesis in limbic and paralimbic structures in patients with depression compared to controls (Rosa-Neto et al, 2004).

In analogy with the neurotrophin hypothesis of depression, low BDNF serum levels were found to be associated with high scores in depressive personality traits in healthy subjects (Lang et al, 2004). In line with this, genetic studies show that a BDNF-coding variant is associated with neuroticism in the NEO personality inventory (Sen et al, 2003). Depressive personality is a trait which has also been connected with low serotonergic neurotransmission (Sen et al, 2004; Heinz et al, 2001). Interpreting the associations between depressive personality trait and low BDNF concentration as well as between low BDNF level and a high $\mathrm{LD}$, one would expect a positive correlation between the LD and depressive personality trait. However, no statistically significant correlation was found in the present study. This may indicate the limitation of the depressive personality trait as a model for affective disorders, since others reported a higher LD in bipolar or unipolar depressive patients (Friedman and Meares, 1979; Brocke et al, 2000), while a lower LD was reported in withdrawn alcohol-dependent patients with high harm avoidance scores, a behavioral characteristic related to depressive personality traits (Herrmann et al, 2002). Therefore, the present results have to be interpreted with caution and should not be generalized to the pathophysiology of depression.

Moreover, one has to bear in mind that BDNF serum changes in subjects with a strong LD or depressed subjects could be an epiphenomenona as the exact mechanisms of regulation of humoral BDNF levels are widely unknown. Platelets, brain neurons, and vascular endothelial cells are considered as candidate sources. A major source of the serum BDNF are platelets, which bind, store, and release BDNF upon activation and in response to coagulation stimuli (Fujimura et al, 2002; Yamamoto and Gurney, 1990). As platelets and neurons develop from a common embryonic precursor in the neural crest (Pearse, 1980), the peripheral BDNF concentration could possibly reflect the central neurotransmission state as it was stated also for serotonergic neurotransmission in platelets (Lesch et al, 1993). A parallel BDNF brain and serum situation is underlined by the finding of Karege et al (2002), who reported a positive correlation between brain and serum BDNF levels in rats, which underwent similar changes during maturation and aging processes and data showing neurotrophic factors from the blood stream can cross the blood-brain barrier under experimental conditions (Pan et al, 1998). However there are also conflicting results, showing that neurotrophins do not cross the blood-brain barrier (Pardridge, 2002).

Although several lines of evidence indicate an association between LD and serotonin (see Introduction), animal investigations reported also some effects of the dopamine and choline system (but not noradrenalin) on the LD (Juckel et al, 1997). Therefore, the moderate correlation between LD and BDNF serum concentration should be viewed with caution. However, the link between LD and serotonin is more consistent and also compatible with a recent animal study showing a high correlation $(r=-0.80)$ between the N1/P2-amplitude and the 5-HT concentration in the auditory cortex (Manjarrez et al, 2001).

In conclusion, the present results are compatible with the hypothesis of enhanced serotonergic neurotransmission in humans with high BDNF serum concentrations. A decrease in serum BDNF levels might reflect low serotonergic neurotransmission and thereby influence the cascade, which may be also relevant in the pathophysiology of depression. However, the results have to be interpreted with caution since the significance is moderate. Moreover, a replication in an independent sample has to be performed.

\section{ACKNOWLEDGEMENTS}

We gratefully acknowledge the excellent technical assistance of Mrs Bunge.

\section{REFERENCES}

Altar CA (1999). Neurotrophins and depression. Trends Pharmacol Sci 20: 59-61.

Altar CA, Boylan C, Fritsche M, Jackson C, Hyman C, Lindsay RM (1994). The neurotrophins NT-4/5 and BDNF augment serotonin, dopamine, and GABAergic systems during behaviorally effective infusions to the substantia nigra. Exp Neurol 130: 31-40.

Biver F, Wikler D, Lotstra F, Dambaut P, Goldman S, Mendlewicz J (1997). Serotonin 5-HT2 receptor imaging in major depression: focal changes in orbito-insular cortex. $\mathrm{Br} J$ Psychiatry 171: 444-448.

Brocke B, Beauducel A, John R, Debener S, Heilemann H (2000). Sensation seeking and affective disorders: characteristics in the intensity dependence of acoustic evoked potentials. Neuropsychobiology 41: 24-30.

Chaouloff F (1994). Influence of physical exercise on 5-HT1A receptor- and anxiety-related behaviours. Neurosci Lett 176: 226-230.

Chaouloff F, Laude D, Guezennec Y, Elghozi JL (1986). Motor activity increases tryptophan, 5-hydroxyindoleacetic acid, and homovanillic acid in ventricular cerebrospinal fluid of the conscious rat. J Neurochem 46: 1313-1316.

Cheetham SC, Katona CLE, Horton RW (1991). Post-mortem studies of neurotransmitter biochemistry in depression and suicide. In: Horton RW, Katona CLE (eds). Biological Aspects of Affective Disorders. Academic Press: London, UK. pp 192-221.

Costa PT, McCrae RR (1992). Revised NEO Personality Inventory and NEO Five-Factor Inventory, Professional Manual. Psychological Assessment Resources: Odessa, Fl.

Dey S, Singh RH, Dey PK (1992). Exercise training: significance of regional alterations in serotonin metabolism of rat brain in relation to antidepressant effect of exercise. Physiol Behav 52: 1095-1099.

D'Sa C, Duman RS (2002). Antidepressants and neuroplasticity. Bipolar Disord 4: 183-194.

Duman RS, Heninger GR, Nestler EJ (1997). A molecular and cellular theory of depression. Arch Gen Psychiatry 54: 597-606.

Eaton MJ, Staley JK, Globus MYT, Whittemore SR (1995). Developmental regulation of early serotonergic neuronal 
differentiation: the role of brain-derived neurotrophic factor and membrane depolarization. Dev Biol 170: 169-182.

Friedman J, Meares R (1979). The effect of placebo and tricyclic antidepressants on cortical evoked potentials in depressed patients. Biol Psychol 8: 291-302.

Fujimura H, Altar CA, Chen R, Nakamura T, Nakahashi T, Kambayashi J et al (2002). Brain-derived neurotrophic factor is stored in human platelets and released by agonist stimulation. Thromb Haemost 87: 728-734.

Gallinat J, Bottlender R, Juckel G, Munke-Puchner A, Stotz G, Kuss $\mathrm{HJ}$ et al (2000). The loudness dependency of the auditory evoked N1/P2-component as a predictor of the acute SSRI response in depression. Psychopharmacology 148: 404-411.

Gallinat J, Mulert C, Bajbouj M, Herrmann WM, Schunter J, Senkowski D et al (2002). Frontal and temporal dysfunction of auditory stimulus processing in schizophrenia. Neuroimage 17: $110-127$.

Gallinat J, Senkowski D, Wernicke C, Juckel G, Becker I, Sander T et al (2003). Allelic variants of the functional promoter polymorphism of the human serotonin transporter gene is associated with auditory cortical stimulus processing. Neuropsychopharmacology 28: 530-532.

Garza AA, Ha TG, Garcia C, Chen MJ, Russo-Neustadt AA (2004). Exercise, antidepressant treatment, and BDNF mRNA expression in the aging brain. Pharmacol Biochem Behav 77: 209-220.

Gjerris A (1988). Baseline studies on transmitter substances in cerebrospinal fluid in depression. Acta Psychiatr Scand Suppl 346: 1-35.

Gur E, Dremencov E, Garcia F, Van de Kar LD, Lerer B, Newman ME (2002). Functional effects of chronic electroconvulsive shock on serotonergic 5-HT(1A) and 5-HT(1B) receptor activity in rat hippocampus and hypothalamus. Brain Res 952: 52-60.

Hegerl U, Bottlender R, Gallinat J, Kuss HJ, Ackenheil M, Moller H] (1998). The serotonin syndrome scale: first results on validity. Eur Arch Psychiatry Clin Neurosci 248: 96-103.

Hegerl U, Juckel G (1993). Intensity dependence of auditory evoked potentials as an indicator of central serotonergic neurotransmission: a new hypothesis. Biol Psychiatry 33: 173187.

Hegerl U, Juckel G, Rao ML, Müller-Oerlinghausen B (1991). Blood serotonin and auditory evoked potentials under fluvoxamine challenge and phototherapy. In: Cassano GB, Akiskal HS (eds). Serotonin-Related Psychiatric Syndromes: Clinical and Therapeutic Links. Royal Society of Medicine Services Limited: New York. pp 163-170.

Heinz A, Mann K, Weinberger DR, Goldman D (2001). Serotonergic dysfunction, negative mood states, and response to alcohol. Alcohol Clin Exp Res 25: 487-495.

Hellweg R, Hock C, Hartung HD (1989). An improved rapid and highly sensitive enzyme immunoassay for nerve growth factor. J Methods Cell Mol Biol 1: 43-49.

Hellweg R, von Armin CAF, Büchner M, Huber R, Riepe MW (2003). Neuroprotection and neuronal dysfunction upon repetitive disinhibition of oxidative phosphorylation. Exp Neurol 183: 346-354.

Herrmann MJ, Sonnek G, Weijers HG, Wiesbeck GA, Boning J, Fallgatter AJ (2002). Electrophysiological indication for a link between serotonergic neurotransmission and personality in alcoholism. Prog Neuropsychopharmacol Biol Psychiatry 26: 157-161.

Juckel G, Hegerl U, Molnar M, Csepe V, Karmos G (1999). Auditory evoked potentials reflect serotonergic neuronal activity - a study in behaving cats administered drugs acting on 5-HT1A autoreceptors in the dorsal raphe nucleus. Neuropsychopharmacology 21: 710-716.

Juckel G, Molnár M, Hegerl U, Csépe V, Karmos G (1997). Auditory evoked potentials as indicators of brain serotonergic activity - first evidence in cats. Biol Psychiatry 41: 1181-1195.
Karege F, Schwald M, Cisse M (2002). Postnatal developmental profile of brain-derived neurotrophic factor in rat brain and platelets. Neurosci Lett 328: 261-264.

Lang UE, Hellweg R, Gallinat J (2004). BDNF serum concentrations in healthy humans are associated with depression-related personality traits. Neuropsychopharmacology 29: 795-798.

Lesch KP, Wolozin BL, Murphy DL, Riederer P (1993). Primary structure of the human platelet serotonin uptake site: identity with the brain serotonin transporter. J Neurochem 60: 23192322.

Malison RT, Price LH, Berman R, van Dyck CH, Pelton GH, Carpenter L et al (1998). Reduced brain serotonin transporter availability in major depression as measured by [123I]-2 betacarbomethoxy-3-beta-(4-iodophenyl)tropane and single photon emission computed tomography. Biol Psychiatry 44: 1090-1098.

Mamounas LA, Altar CA, Blue ME, Kaplan DR, Tessarollo L, Lyons WE (2000). BDNF promotes the regenerative sprouting, but not survival, of injured serotoninergic axons in the adult rat brain. J Neurosci 20: 771-782.

Mamounas LA, Blue ME, Siuciak JA, Altar CA (1995). Brainderived neurotrophic factor promotes the survival and sprouting of serotonergic axons in rat brain. J Neurosci 15: 7929-7939.

Manjarrez GG, Hernandez ZE, Robles OA, Gonzalez RM, Hernandez RJ (2001). Developmental impairment of auditory evoked N1/P2 component in rats undernourished in utero: its relation to brain serotonin activity. Brain Res Dev Brain Res 127: 149-155.

Manji HK, Quiroz JA, Sporn J, Payne JL, Denicoff KA, Gray N et al (2003). Enhancing neuronal plasticity and cellular resilience to develop novel, improved therapeutics for difficult-to-treat depression. Biol Psychiatry 53: 707-742.

Meeusen R, Thorre K, Chaouloff F, Sarre S, De Meirleir K, Ebinger $\mathrm{G}$ et al (1996). Effects of tryptophan and/or acute running on extracellular 5-HT and 5-HIAA levels in the hippocampus of food-deprived rats. Brain Res 740: 245-252.

Mössner R, Daniel S, Albert D, Heils A, Okladnova O, Schmitt A et al (2000). Serotonin transporter function is modulated by brain-derived neurotrophic factor (BDNF) but not nerve growth factor (NGF). Neurochem Int 36: 197-202.

Nibuya M, Morinobu S, Duman RS (1995). Regulation of BDNF and trkB mRNA in rat brain by chronic electroconvulsive seizure and antidepressant drug treatments. J Neurosci 15: 7539-7547.

Owens MJ, Nemeroff CB (1994). Role of serotonin in the pathophysiology of depression: focus on the serotonin receptor. Clin Chem 40: 288-295.

Pan W, Banks WA, Fasold MB, Bluth J, Kastin AJ (1998). Transport of brain-derived neurotrophic factor across the blood-brain barrier. Neuropsychopharmacol 37: 1553-1561.

Pardridge WM (2002). Neurotrophins, neuroprotection and the blood-brain barrier. Curr Opin Investig Drugs 3: 1753-1757.

Pearse AG (1980). The common peptides and the cytochemistry of their cells of origin. Basic Appl Histochem 24: 63-73.

Petty F, Davis LL, Kabel D, Kramer GL (1996). Serotonin dysfunction disorders: a behavioral neurochemistry perspective. J Clin Psychiatry 57(Suppl 8): 11-16.

Rosa-Neto P, Diksic M, Okazawa H, Leyton M, Ghadirian N, Mzengeza $S$ et al (2004). Measurement of brain regional alpha$\left[{ }^{11} \mathrm{C}\right]$ methyl-L-tryptophan trapping as a measure of serotonin synthesis in medication-free patients with major depression. Arch Gen Psychiatry 61: 556-563.

Rumajogee P, Madeira A, Vergé D, Hamon M, Miquel MC (2002). Up-regulation of the neuronal serotoninergic phenotype in vitro: BDNF and cAMP share TrkB-dependent mechanisms. J Neurochem 83: 1525-1528.

Russo-Neustadt A (2003). Brain-derived neurotrophic factor, behavior, and new directions for the treatment of mental disorders. Semin Clin Neuropsychiatry 8: 109-118. 
Russo-Neustadt AA, Beard RC, Huang YM, Cotman CW (2000). Physical activity and antidepressant treatment potentiate the expression of specific brain-derived neurotrophic factor transcripts in the rat hippocampus. Neuroscience 101: 305-312.

Schildkraut JJ (1965). The catecholamine hypothesis of affective disorders: a review of the supporting evidence. Am J Psychiatry 122: 509-521.

Sen S, Nesse RM, Stoltenberg SF, Li S, Gleiberman L, Chakravarti A et al (2003). A BDNF coding variant is associated with the NEO personality inventory domain neuroticism, a risk factor for depression. Neuropsychopharmacology 28: 397-401.

Sen S, Villafuerte S, Nesse R, Stoltenberg SF, Hopcian J, Gleiberman L et al (2004). Serotonin transporter and GABAA alpha 6 receptor variants are associated with neuroticism. Biol Psychiatry 55: 244-249.

Senkowski D, Linden M, Zubrägel D, Bär T, Gallinat J (2003). Evidence for disturbed cortical signal processing and altered serotonergic neurotransmission in generalized anxiety disorder. Biol Psychiatry 53: 304-314.

Sheehan DV, Lecrubier Y, Sheehan KH, Amorim P, Janavs J, Weiller E (1998). The Mini-International Neuropsychiatric Interview (M.I.N.I.): the development and validation of a structured diagnostic psychiatric interview for DSM-IV and ICD-10. J Clin Psychiatry 59: 22-33.

Shen H, Numachi Y, Yoshida S, Toda S, Awata S, Matsuoka $\mathrm{H}$ et al (2001). Electroconvulsive shock regulates serotonin transporter mRNA expression in rat raphe nucleus. Psychiatry Clin Neurosci 55: 75-77.
Shirayama Y, Chen AC, Nakagawa S, Russell DS, Duman RS (2002). Brain-derived neurotrophic factor produces antidepressant effects in behavioral models of depression. J Neurosci 22: 3251-3261.

Siuciak JA, Boylan C, Fritsche M, Altar CA, Lindsay RM (1996). BDNF increases monoaminergic activity in rat brain following intracerebroventricular or intraparenchymal administration. Brain Res 710: 11-20.

Siuciak JA, Clark MS, Rind HB, Whettemore SR, Russo AF (1998). BDNF induction of tryptophan hydroxylase mRNA levels in the rat brain. J Neurosci Res 52: 149-158.

Siuciak JA, Lewis DR, Wiegand SJ, Lindsay RM (1997). Antidepressant-like effect of brain-derived neurotrophic factor (BDNF). Pharmacol Biochem Behav 56: 131-137.

Stanley M, Mann JJ (1983). Increased serotonin-2 binding sites in frontal cortex of suicide victims. Lancet 1: 214-216.

Tuchtenhagen F, Daumann J, Norra C, Gobbele R, Becker S, Pelz S et al (2000). High intensity dependence of auditory evoked dipole source activity indicates decreased serotonergic activity in abstinent ecstasy (MDMA) users. Neuropsychopharmacology 22: 608-617.

von Knorring L, Perris C (1981). Biochemistry of the augmentingreducing response in visual evoked potentials. Neuropsychobiology 7: $1-8$.

Yamamoto H, Gurney ME (1990). Human platelets contain brainderived neurotrophic factor. J Neurosci 10: 3469-3478.

Yates M, Leake A, Candy JM, Fairbaim AF, McKeith IG, Ferrier IN (1990). 5HT2 receptor changes in major depression. Biol Psychiatry 27: 489-496. 